\title{
O jovem Nietzsche e as influências de Lange ${ }^{1}$ The young Nietzsche and the influences of Lange
}

\author{
NEOMAR SANDRO MIGNONI ${ }^{2}$
}

\begin{abstract}
Resumo: O presente estudo visa a tematizar a influência da obra de Lange no jovem Nietzsche enquanto ainda era estudante de Filologia Clássica em Leipzig, por volta de 186668. Procuraremos evidenciar que a História do Materialismo ocupa um lugar central entre as principais fontes de informação a partir da qual o jovem Nietzsche pode levar a cabo uma série de leituras, especialmente sobre a ciência do seu tempo, que serão fundamentais e determinantes no plano da elaboração de seus principais escritos dos anos de 1870 .
\end{abstract}

Palavras-chave: Nietzsche. Lange. Schopenhauer. Ciência.

Abstract: The present study aims to thematize the influence of Lange's work on young Nietzsche while still a student of Classical Philology in Leipzig, circa 1866-68. We will try to show that the History of Materialism occupies a central place among the main sources of information from which the young Nietzsche can carry out a series of readings, especially on the science of his time, which will be fundamental and decisive in the elaboration plan of his main writings of the $1870 \mathrm{os}$.

Keywords: Nietzsche. Lange. Schopenhauer. Science.

Ao abandonar o curso de Teologia em Bonn e decidir estudar filologia clássica em Leipzig, onde permaneceu do outono de 1865 até a primavera de 1869, Nietzsche dedicou-se a uma temporada de estudos bastante decisiva. Durante esse período, no qual a filologia tornou-se parte essencial de sua vida, assomaram-se as descobertas da obra de Arthur Schopenhauer e de Friedrich Albert Lange. De Schopenhauer, Nietzsche deve ter lido $O$ mundo como vontade e representação entre o final de agosto até o início de novembro de 1865 e seu efeito foi imediato. Não muito diferente foi o encantamento do jovem e futuro filólogo com a História do Materialismo de Lange, obra que adquiriu logo após sua publicação em agosto de 1866, lendo-a inteiramente em um breve período.

O pessimismo schopenhaueriano e a negação da vontade como exigência ética encantaram o jovem Nietzsche. $\mathrm{O}$ entusiasmo com essa influência se tornou visível no seu modo de pensar e conceber o mundo especialmente ao longo dos anos de 1865-66. Tais influxos encontram-se presentes inclusive em suas cartas, como, por exemplo, a que escreveu ao seu amigo Hermam Mushacke de 11 de julho de 1866 : "Desde que Schopenhauer nos tirou dos olhos a venda do otimismo vemos com maior nitidez. A vida é mais interessante, embora mais feia”. Schopenhauer desperta

\footnotetext{
${ }^{1}$ O presente trabalho foi realizado com apoio da Coordenação de Aperfeiçoamento de Pessoal de Nível Superior - Brasil (CAPES) - código de Financiamento oo1.

${ }^{2}$ Graduado em Filosofia pela UNICENTRO. Mestre em Filosofia pela UNIOESTE. Doutorando em Filosofia pela UNIOESTE. E-mail: neomarmignoni@hotmail.com.
} 
Nietzsche para o pensamento filosófico persuadindo-o de entranhar-se unicamente na filologia, como era o desejo de seu professor Ritschl. Na filosofia de Schopenhauer, Nietzsche encontrou filosoficamente manifestado o conteúdo trágico da vida, cujo ímpeto lhe revelou, por meio da arte e de sua ciência, toda a tragédia antiga (cf. JANZ, I, 2016, p.153). Embora não tenha produzido nada de filosófico nesses primeiros anos em Leipzig, o aprofundamento na filosofia de Schopenhauer contribuiu para que Nietzsche buscasse ampliar seus conhecimentos sobre a história da filosofia em geral.

Contudo, ainda que o filósofo mantivesse um vivo interesse pela filosofia que agora se materializava no estudo de Schopenhauer de um lado, por outro, seu interesse pelo materialismo e especialmente pela figura de Demócrito se fortalecia. Incentivado sobretudo, por seu distanciamento do cristianismo, das leituras de Feuerbach e da revista Anregungen für Kunst, Leben und Wissenschaft, Nietzsche ocupou-se ainda com a crítica à teleologia e ao estudo da natureza da arte, especialmente da música, leu David Strauss, o qual discutiu com a irmã, o cientista da música de Viena e adversário de Wagner, Eduard Hanslick, além do ensaísta e poeta americano Ralph W. Emerson. No entanto, nenhuma dessas leituras foram tão impactantes quanto a leitura da Geschichte des Materialismus und Kritik seiner Bedeuting in der Gegenwart (Inserlohn, 1866) ou, simplesmente História do materialismo, de Friedrich Albert Lange.

Imbuída de uma detalhada reconstrução das teorias científicas modernas, em particular da fisiologia e da biologia, a História do materialismo tornou-se crucial, pois, através dela, o jovem estudante de filologia pôde aprofundar-se na relação entre as ciências naturais e a filosofia, familiarizando-se com o darwinismo ${ }^{3}$ e com as vertentes políticas e econômicas de seu tempo, ao mesmo tempo em que encontrava ali também um aparato bastante amplo acerca do materialismo, fundamentado, em partes, na figura de Demócrito, um dos pensadores prediletos de Lange e que, nesse período, tanto interessava a Nietzsche. Foi também através da obra de Lange que o jovem Nietzsche travou contato pela primeira vez com os positivistas ingleses, além de encontrar ainda uma outra interpretação acerca de Kant, diversa daquela apresentada por Schopenhauer. Mais tarde ele retomaria seu interesse por Kant por meio da obra de Kuno Fischer (Immanuel Kant, Entwicklungsgeschichte und System der kritischen Philosophie, 2 vol.) e possivelmente na leitura da própria Crítica da Faculdade do Juízo.

Lange não foi apenas uma referência acerca da história da filosofia ou de seus conceitos gerais, foi, antes de tudo, uma fonte de informações sobre as orientações e os contributos da ciência de sua época. Tais informações determinaram de modo bastante profundo os rumos da investigação de Nietzsche no âmbito científico, uma

\footnotetext{
${ }^{3}$ Mittasch (1952, p. 13) é categórico em afirmar que foi através da obra de Lange que Nietzsche obteve um preciso conhecimento sobre o darwinismo.
} 
vez que, além de apresentar as principais temáticas debatidas no momento em História do Materialismo, trouxe informações bastante detalhadas dos autores mais influentes do período. Numa carta endereçada à Gersdorff em fevereiro de 1868, Nietzsche reconheceu a importância dessa obra numa verdadeira síntese:

Se você tiver vontade de se informar completamente sobre o movimento materialista dos nossos dias, sobre as ciências naturais e suas teorias darwinianas, os seus sistemas cósmicos, com sua câmera obscura animada, mas também sobre o materialismo ético, sobre a teoria de Manchester etc., não tenho nada de mais extraordinário para te recomendar que a História do Materialismo de Friedrich Albert Lange, um livro que oferece infinitamente mais do que promete no título e que não nos cansamos de ler e consultar como um verdadeiro tesouro. Em vista da orientação de seus estudos, não posso lhe recomendar nada mais digno. Eu estou firmemente decidido a apresentar-me a este homem e, como sinal de minha gratidão, pretendo enviar-lhe meu tratado sobre Demócrito (Epistolario, I, 562).

Nietzsche não chegou a escrever tal Tratado, nem mesmo encontrar-se pessoalmente com Lange, embora estivessem bastante próximos geograficamente, visto que, entre os anos de 1870 e 1872, Lange vivia em Zurique e Nietzsche na Basileia (cf. JANZ, 1980, p. 181-82) ${ }^{4}$. Entretanto, isso não impediu Nietzsche de manter um forte interesse sobre a obra de Lange ao longo dos anos, pois, ao que tudo indica, ele tornou a ler a obra por volta de $1884-85$, como nos atestam alguns póstumos ${ }^{5}$, o que nos leva a pressupor que o filósofo tenha tomado conhecimento da segunda edição da obra ampliada e reelaborada publicada em 1882. Os exemplares da primeira edição (1866) foram doados pelo filósofo ao seu amigo Heinrich Romundt ainda nos anos de 1870 . Na biblioteca de Nietzsche, encontra-se segunda reimpressão da quarta edição publicada em 1887 por Hermann Cohen ${ }^{6}$. Nietzsche cita muito raramente Lange em seus escritos, apesar de toda a influência, o que torna ainda mais difícil identificar e analisar a influência de Lange sem o apoio de referências e menções à obra. Por conta disso, talvez o modo mais adequado

\footnotetext{
${ }^{4}$ Lange até chegou a citar Nietzsche numa nota na segunda edição de sua obra (vol I., nota 44, p. 6o), porém Nietzsche não chegou a ter conhecimento dessa referência, pois a versão que ele adquiriu em 1887, nada mais era do que uma edição econômica da quarta edição da obra de Lange editada em um único volume por $\mathrm{H}$. Cohen. Embora essa quarta edição adquirida por Nietzsche seja uma reprodução fiel do texto da segunda edição ela não reproduziu as notas da segunda edição. Inclusive na primeira tiragem, não havia nem mesmo o índice dos autores citados. A segunda tiragem passou a contar com o índice de nomes, porém o nome de Nietzsche não chegou a aparecer, pois, como já dissemos, ela não reproduziu as notas existentes na segunda edição (cf. SALAQUARDA, 1992, p. 2425).

${ }^{5}$ Cf. FP 25 [318] e 25[424] da primavera de 1884 e 34[99] de abril - junho de 1885.

${ }^{6} \mathrm{Cf}$. Nietzsches persönaliches Bibliothek, p. 339.
} 
consista em seguir os motivos e os temas singulares tratados por Lange e pelo filósofo no intuito de encontrar possíveis conexões ao longo da obra nietzschiana ${ }^{7}$.

Ainda que Lange não desenvolva todas as implicações e consequências de suas análises filosóficas, Nietzsche certamente encontrou ali um extenso número de questões e temas que o preocupavam. De acordo com Stack (1983, p. 17-18), a visão geral de Lange carrega consigo a ideia de que o surgimento do materialismo juntamente com o desenvolvimento da Naturwissenschaft levou a um ponto que existe "uma restrição do verdadeiro conhecimento (como em Kant) dos próprios fenômenos". Apesar do progresso no desenvolvimento do intelecto humano, isso leva a ciência natural a encontrar, paradoxalmente, os "limites do conhecimento científico natural". Aos olhos de Lange, tais consequências, advindas do avanço das teorias científicas, constituem uma confirmação da crítica da teoria do conhecimento de Kant. Nesse sentido, "o agnosticismo filosófico se funde com o agnosticismo científico" de modo que quanto mais se sonda da natureza, menos se conhece a respeito das constituintes finais da realidade. Para Lange, a ciência pode viver com esse agnosticismo, mas uma cultura ou uma civilização não conseguem sobreviver por muito tempo sem uma religião ou uma natureza religiosa.

Lange estabelece, assim, um diagnóstico bastante preciso quanto às consequências e perigos oriundos de uma visão de mundo totalmente pautada no científico e que pudesse alcançar o domínio cultural. A previsão de intensos conflitos entre ciência e religião ou das tensões em torno das questões sociais é algo presente em Lange, e que mais tarde fará parte também do repertório de Nietzsche. A solução de Lange passa por um ideal cultural pós-cristão que não apenas congregue e unifique cultura ocidental, mas que também consiga dar significado à vida para além da frieza das probabilidades científicas. Nisso talvez esteja a grandeza de Lange, cujo reconhecimento por parte de Nietzsche é notório. Mesmo simpatizando-se com o materialismo, mesmo tendo-o examinado cuidadosamente, Lange não se deixa levar pela via do mero dogmatismo materialista. Antes, ainda que partam de um ponto de vista do materialismo, suas soluções buscam transcender o próprio materialismo. Ou seja, Lange se manteria numa espécie de terceira via entre o materialismo e o idealismo que Stack denomina de fenomenalismo universal ${ }^{8}$. Por reconhecer que a objetividade do real é importante à

\footnotetext{
${ }^{7}$ Exemplo de um trabalho dessa natureza é, sem dúvidas, a obra de G. J. Stack, Lange and Nietzsche, na qual são investigadas as singulares temáticas do pensamento de Nietzsche em relação a Lange dentre elas questões relativas ao conhecimento e à verdade, à teoria do eterno retorno do mesmo, à vontade de potência. A partir delas e sem desmerecer a originalidade do filósofo, o autor evidencia a maneira pela qual a profunda conexão entre a obra de Lange e os escritos de Nietzsche se conectam entre si e de como, em alguns casos, aparenta que o filósofo tenha desenvolvido tais teorias a partir de conteúdos ainda embrionários presentes na História do materialismo.

${ }^{8}$ Salaquarda (1979, p. 142) defende que Nietzsche foi influenciado por esse fenomenalismo de Lange, porém somente com a publicação de Humano Demasiado Humano I ele se tornaria público. Segundo ele, Nietzsche chegou a dar sinais dessa influência em outros de seus escritos como, por exemplo, Verdade e mentira no sentido extra-moral e Sobre o Pathos da Verdade (um dos "Cinco prefácios para
} 
ciência assim como ao homem é necessária uma cultura ideal de valores, Lange procuraria uma espécie de harmonia entre o Wissenschaften e o Geisteswissenschaft numa atitude que anteciparia muitas tendências do final do século XIX e início do XX (cf. STACK, 1983, p. 18).

Isso certamente permitiu o jovem filólogo expandir seu pensamento sob um vasto terreno sobre o qual pode desenvolver muitos aspectos de sua filosofia ainda em fase experimental. Talvez seja sob essa perspectiva que Nietzsche se refira à História do materialismo como um "verdadeiro tesouro" (Epistolario, I, 562), uma vez que o fenomenalismo, o ceticismo, a ideia de que a ciência não nos oferece uma "verdade", bem como a crítica das verdades "em si", com as quais Nietzsche se confronta, podem ser encontradas, ainda que de forma embrionária, no pensamento de Lange. Ao estabelecer sua crítica do empreendimento científico pela via filosófica, Lange tornou visível à Nietzsche que a reflexão filosófica pode alcançar um profundo valor ao compreender tanto os aspectos materiais quanto os espirituais. Desse modo, todo e qualquer empreendimento filosófico que pretenda dar conta da realidade não pode eximir-se de considerar o longo e vasto acúmulo de conhecimento advindo das ciências. Provavelmente Nietzsche tenha compreendido tal proposito, uma vez que desde o período de sua formação, quando descobriu Lange, dedicou-se assiduamente à filosofia confrontando-se constantemente com a problemática científica, sem esquecer os aspectos mais ideais da vida humana, como por exemplo, a arte, a religião e a metafísica. Sob esse aspecto, parece-nos que o viés argumentativo de Humano, demasiado humano (sobretudo o §251) seja o exemplo mais palpável de tais influências.

Nesse sentido, assim como Brobjer (2016, p. 26) podemos afirmar que a descoberta de Schopenhauer em 1865 juntamente com a descoberta de Lange em 1866, mais do que despertar e Nietzsche para a filosofia revelou-se determinante para o seu crescente interesse acerca das ciências naturais. Desse modo, Lange foi tão crucial para o debate de Nietzsche com o pensamento científico quanto Schopenhauer o foi no campo da filosofia. Foi também através de Lange e Schopenhauer que Nietzsche aprofundou-se, num primeiro momento, na filosofia de Kant, sua terceira grande influência desse período. Não é à toa que tenha escrito "Kant, Schopenhauer e este livro de Lange - de nada mais preciso" (Epistolario, I, 526) na carta à Mushacke.

A influência de Kant em Nietzsche, especialmente nesses anos de Leipzig é grande, mesmo que o jovem estudante não o tenha lido em primeira mão, pois, ao contrário de Schopenhauer e Lange de quem leu as próprias obras, o conhecimento sobre o filósofo de Königsberg, se deu, na maior parte, a partir de fontes

cinco livros não escritos"), o qual foi entregue a Cosima Wagner como presente de natal e aniversário em 1872, porém diante da reserva e da frieza com que os Wagners receberam tal escrito é bastante provável que ele tivesse decidido manter-se em silêncio tanto quanto possível sobre isso. 
secundárias. Kant é também um dos filósofos a quem Nietzsche mais faz referências, seja porque é a partir dele que se desenvolve quase toda a filosofia alemã posterior, da qual Schopenhauer e Lange fazem parte, seja porque grande parte da sua crítica à filosofia moderna, incluída aqui a alemã, é dirigida a Kant ou levada a termo a partir de Kant. Imediatamente após tomar conhecimento sobre Kant, Nietzsche demonstrou um profundo interesse pelo filósofo, e, como procuramos evidenciar acima, chegou inclusive a planejar uma dissertação filosófica "metade científica e metade filosófica" relacionada ao filósofo (cf. Epistolario, I, 568). Anos mais tarde, já em sua filosofia tardia, Kant viria a tornar-se um de seus principais antípodas, denominado de "o grande chinês de Königsberg"9 (BM, §210), a quem dirige muitas das suas críticas.

Para compreender essa mudança de perspectiva, é imprescindível que se leve em conta as leituras feitas sobre Kant. Provavelmente o primeiro contato com a filosofia de Kant tenha se dado através de Schopenhauer que, além da grande influência kantiana, também discutiu vários argumentos de Kant em seus escritos. Por outro lado, é bastante provável que o entusiasmo de Nietzsche para com Kant tenha sido motivado também pela leitura da obra de Lange. A História do materialismo divide-se em dois volumes cuja argumentação sobre o materialismo divide-se em "antes de Kant" (vol. I) e "depois de Kant" (vol. II). Lange era assumidamente kantiano e além da centena de páginas dedicadas ao filósofo, ainda manteve um profundo diálogo com o autor ao longo de toda a obra, especialmente no segundo volume.

Uma terceira e talvez bastante decisiva fonte que Nietzsche se utilizou sobre Kant é a Geschichte der neuern Philosophie de Kuno Fischer, que dedica os volumes III e IV a Immanuel Kant. Entwicklungsgeschischte und System der kritischen Philosophie (Mannheim, 1860), provavelmente lida entre outubro de 1867 e abril de 1868. Muitas das citações de Kant são advindas da obra de Fischer que também é citado por Nietzsche repetidas vezes ${ }^{10}$. Há ainda uma outra fonte secundária que possivelmente também tenha contribuído para com Nietzsche no conhecimento sobre Kant. Trata-se da obra Über die Natur der Cometen: Beiträge zur Geschichte und Theorie der Erkenntnis (1872) de Johann K. Zöllner, na qual encontram-se algumas dezenas de páginas acerca de Kant.

\footnotetext{
9 "O grande chinês de Königsberg" (BM, §210) e "Chinesismo Königsberniano" (CI, §11), "Königsberniana" (CI, Como o "mundo verdadeiro" se tornou finalmente em fábula) são evidentemente referências a Kant. Para melhor compreender a designação recorde-se a crítica de Nietzsche à Kant enquanto moralista, evidenciada, por exemplo, no \$11 do Anticristo, levando-se em conta ainda que a China é, para Nietsche, "um país onde a insatisfação em grande escala e a capacidade de mudança se extinguiram séculos atrás” (GC, §24).

${ }^{10}$ Nietzsche também faz referências a Friedrich Überweg especialmente a Grundriss der Geschichte der Philosophie des Alterthums e Grundriss der Geschichte der neueren Philosophie. Na Biblioteca de Nietzsche, além dessa obra de Überweg, encontra-se também Kant und die Epigonen de Otto Liebmann (Stuttgart, 1865) (cf. Nietzsches persönaliche Bibliothek, p. $627-28$ e 356 respectivamente).
} 
Na Biblioteca de Nietzsche, não encontramos nenhum volume de Kant e provavelmente ele nunca possuiu algum. No entanto, é possível que o filósofo tenha lido a Kritik der Urtheilskraft (Crítica da faculdade do Juízo) em 1868. Embora não temos provas robustas dessas leituras, diante do entusiasmo bastante expressivo presente em seus escritos juntamente com os registros de suas inúmeras leituras de obras sobre Kant, que aliados à sua intenção de produzir uma dissertação filosófica cuja temática girava em torno de Kant e a teleologia e que resultaram em inúmeras citações acerca do filósofo, parece-nos aceitável semelhante hipótese. Na carta que escreveu a Wilhelm Vischer (-Bilfinger), provavelmente em janeiro de 1871, justificando sua candidatura à cátedra de filosofia na Universidade da Basileia, Nietzsche também afirma que "dentre os filósofos recentes estudei com predileção particular Kant e Schopenhauer" (Epistolario, II, 118).

Seja como for, é inegável que as influências de Kant, Schopenhauer e de Lange determinaram os estudos de Nietzsche. Obviamente que junto deles se podem citar inúmeros outros, como, por exemplo, Überweg e Fischer, porém a importância de Kant, Schopenhauer e Lange será bastante decisiva ao longo desse percurso que compreende os anos da Basileia (1869-1879) e em especial no triênio 1875-78, quando Nietzsche elabora e traz à luz Humano, demasiado humano. Isso porque, a partir de Lange, Nietzsche toma conhecimento de muitos autores do campo científico que, de um modo outro de outro, acabam se inserindo num contexto filosófico profundamente determinado pela discussão acerca de Kant e Schopenhauer.

Um outro fator determinante para a compreensão da importância que a ciência e, quem sabe até o naturalismo, tem para Nietzsche é, mais uma vez, a figura de Demócrito. Foi através do filósofo grego que o atomismo, o materialismo e a questão da teleologia se tornaram importantes para Nietzsche. É bastante provável que Nietzsche tenha conhecido Demócrito antes de Lange, mas foi através da História do materialismo que ele passa a se dedicar ao filósofo grego com interesses filológicos e filosóficos. Recorde-se a já citada carta à Gerdorff (Epistolario, I, 562), na qual pretendia enviar seu tratado sobre Demócrito a Lange em sinal de gratidão. Os cadernos de Nietzsche, escritos depois da leitura de Lange, contemplam uma série de anotações que provavelmente seriam utilizadas no ensaio ${ }^{11}$.

A análise desses cadernos evidencia que, além de Demócrito, encontram-se presentes ainda os demais temas com os quais Nietzsche se ocupou neste triênio de

\footnotetext{
${ }^{11}$ Veja-se, por exemplo, o caderno $P$ I 4 a do outono de 1867 - primavera de 1868 que contém os apontamentos específicos para este ensaio. No caderno $P$ I $6 a$, por exemplo, Nietzsche continua a tematizar sobre Demócrito, além de fazer uma série de referências a outros autores como La Mettrie, Gassendi, Locke, Epicuro, Lucrécio entre outros, os quais são seguidos por uma série de citações advindas da História do Materialismo de Lange. Aliás, esses autores são os mesmos que Lange tematiza ao longo de sua obra, o que mais uma vez reforça a importância deste autor para o desenvolvimento da filosofia de Nietzsche, sobretudo à temática científica (cf. NIETZSCHE, 1993 p. 66-106).
} 
1865-68. Esses assuntos, além de concomitantes, possuem como elemento aglutinador um modelo argumentativo muito próximo de Lange com os quais se mesclam os argumentos de Schopenhauer, Kant e Demócrito ${ }^{12}$. Nesse sentido, parece-nos bastante claro que a proeminência do modelo proveniente da História do materialismo deve-se, sobretudo, pela atualidade e pertinência com que seu autor discute e interpõe suas questões, as quais se tornaram fundamentais a Nietzsche, que, por sua vez, as tematiza a partir dos mesmos autores e assuntos que foram citados exclusivamente por Lange frente aos demais autores que o filósofo leu e consultou nesse período ${ }^{13}$.

Segundo Gori (2007, p. 45), a influência que o texto de Lange teve sobre Nietzsche advém da abordagem filosófica feita pelo autor da História do Materialismo no confronto com a interpretação materialista da natureza. Partindo de Demócrito enquanto expressão primeira desse pensamento, Lange não se ateve às temáticas científicas de maneira rigorosa, mas antes as reelaborou desenvolvendo suas consequências tanto no âmbito gnosiológico quanto ético. Segundo o mesmo autor, essa abordagem de Lange é o resultado do contexto no qual vivia, associado à profunda influência de Kant ${ }^{14}$. Nesse sentido, essa seria também a razão pela qual o estudo sobre o aprofundamento da realidade natural torna-se o ponto de partida para uma reflexão que deseja ser profundamente filosófica, mantendo-se à parte da especulação científica sem, contudo, contrapor-se a ela.

No entanto, esse modo de proceder, até então característico de Lange, reaparece agora também nos escritos de Nietzsche, e não apenas nesses da juventude, mas também nos posteriores, como por exemplo, nos seus primeiros escritos e lições da Basileia, mantendo-se inclusive até mesmo nos escritos da maturidade, o que prova mais uma vez que a influência de Lange é algo de profundo e duradouro. Nessa direção, podemos afirmar, tal qual Salaquarda (1992, p. 28), que

\footnotetext{
${ }^{12}$ Note-se que os de cadernos do outono de 1867 - da primavera de 1868 trazem uma sequência de temas e de autores. Por exemplo, o caderno $\mathrm{PI}_{4}$ a, como evidenciamos acima, trata de Demócrito, da mesma forma que o P I 6 a que mescla desde Demócrito, La Mettrie, Gassendi, Locke, Epicuro, Lucrécio e Lange. Nesse mesmo caderno ele escreve o Sobre Schopenhauer com críticas ao autor. No caderno $P$ I 7 a torna a falar de Demócrito e inclui discussões sobre a ciência, e aqui temos referências à química, medicina, até chegar à temática da teleologia que será aprofundada no caderno seguinte, o P I 8 a que traz o projeto de dissertação $A$ teleologia de Kant em diante. Em todos esses escritos não é difícil perceber o quanto as obras de Schopenhauer, Fischer e Lange, com a proeminência deste último, se mesclam num único agregado (cf. NIETZSCHE, 1993, p. 66-162).

${ }^{13}$ Referimo-nos a temáticas que comportam desde o radicalismo materialista, Darwin, as questões sobre a teleologia e a explicação mecanicista de mundo cuja problematização de Lange gira em torno do materialismo e, por vezes, relacionando Darwin a Demócrito. Nesse sentido, recomenda-se a leitura da introdução feita por Giuliano Campioni e Federico Gerratana ao volume Appunti Filosofici 1867-1869 - Omero e la Filologia Clássica, Adelphi, 1993, p. 9-54. Nesse volume, também se encontram os cadernos de Nietzsche aqui citados.

${ }^{14}$ Nesse caso vale lembrar que Lange divide sua obra em dois volumes, sendo que no segundo toda a abordagem gira em torno do "Materialismo de Kant", que inclusive é o subtítulo desse volume. Para Gori (2007, p. 45), Lange dividiria assim a história da ciência em "antes de Kant" e "depois de Kant" o que evidencia ainda mais a importância que Lange atribui a Kant.
} 
é a partir das indicações de Lange que Nietzsche conhece aquela diversidade de autores e obras aos quais foi endereçado e lhe proporcionaram o conhecimento de linhas inteiras de pesquisa. É certo também que, em alguns casos e sobre determinados autores, lhe bastaram as exposições e interpretações de Lange, porém, em outros, Nietzsche tratou de ler e estudar as próprias obras desses autores confrontando-se com elas sem intermediações ${ }^{15}$.

Sob as influências da História do materialismo, Nietzsche sentiu-se compelido a debruçar-se sobre um dos argumentos mais debatidos naquele momento, as ciências naturais $^{16}$. Frente às numerosas descobertas científicas daquele período, as quais garantiram um rápido progresso à pesquisa científica, era natural que surgissem intensos debates. Diante das novas possibilidades e perspectivas, tornavam-se urgentes as explicações que pudessem resolver as questões que agora se impunham diante do homem em sua relação com o mundo natural. Foi então que a obra de Lange possibilitou a Nietzsche, sempre muito atento aos debates culturais que o cercavam, confrontar-se com os novos problemas humanos e científicos de seu tempo, os quais irrompiam trazendo consigo as consequências e as influências de uma nova era para a história, a sociedade e a vida como um todo (cf. ZIMMERLI, 1999, p. 255) ${ }^{17}$.

À medida que descobre novas exigências, novas discussões e problemas cada vez mais aprofundados a partir dos temas que vinha se debruçando, Nietzsche sente a necessidade de expandir seus estudos a novas obras e autores. Alwin Mittasch, em seu estudo intitulado Friedrich Nietzsches als Naturphilosoph (1952, p. 13-23), foi quem pela primeira vez evidenciou que o interesse de Nietzsche pelas temáticas científicas se desenvolveu nesses anos de estudos em Leipzig. É também durante esse período que o filósofo conquista uma certa independência em relação à mãe e a irmã, se aproxima de Ritschl que, além da influência exercida, foi também determinante para o seu ingresso, como professor, na universidade da Basileia. Nietzsche ainda permanece bastante apegado a Schopenhauer, quem, além do despertar à filosofia, também representou uma profunda experiência espiritual que se revelou duradoura. É a partir desse contexto, portanto, que Nietzsche projeta

\footnotetext{
${ }^{15}$ Sobre esse argumento, é fundamental a leitura de J. Salaquarda, Nietzsche und Lange publicado no Nietzsche-Studien, vol. 7, 1978, p. 236-253. O mesmo texto pode ser lido também em versão italiana Nietzsche e Lange, in La 'Biblioteca ideale' di Nietzsche, a cura di Giuliano Campioni e Aldo Venturelli, Napoli, Guida editori, 1992, p. 19-43.

${ }^{16}$ Para Mittasch (1952, p. 13-14), Nietzsche conhecia a ideia de desenvolvimento natural (natürlicher Entwicklung) desde Pforta, mas teria sido apenas em Leipzig, depois da leitura da obra de Lange, que ele viera a ocupar-se verdadeiramente com o assunto que agora dominava o cenário das ciências naturais. O autor destaca ainda, como já citamos, que a obra de Lange foi crucial para seu conhecimento sobre o Darwinismo.

${ }^{17}$ Para Zimmerli (1999, p. 255), Nietzsche pode ser denominado como um "filósofo da ciência", uma vez que, segundo ele, a análise dos escritos do filósofo evidencia que a maior preocupação de sua filosofia gira em torno dos problemas mais decisivos do século XIX, o da ciência e das humanidades, os quais, além de intimamente coligados, também poderiam ser caracterizados a partir do termo alemão Wissenschaft.
} 
uma série de leituras cujas obras refletem, em certa medida, seus interesses no período. Conforme a reconstrução de Mittasch (1952, p. 21-22), feita a partir das anotações do jovem estudante, o quadro de leituras divide-se em tratados de medicina, fisiologia, lógica e ciências da natureza, conforme o elenco abaixo:

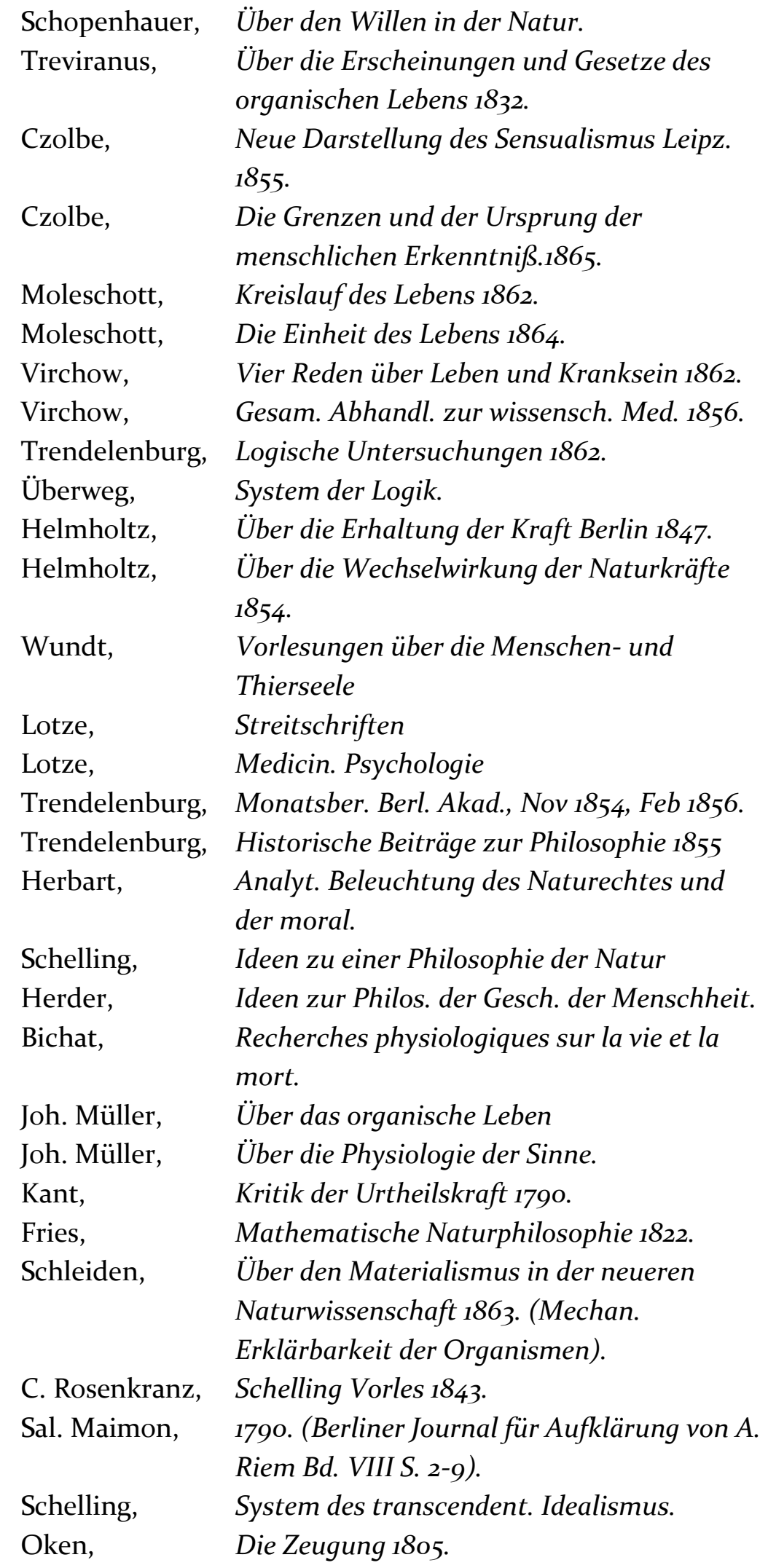




$\begin{array}{ll}\text { Oken, } & \text { Lehrbuch der Naturphilosophie 1809 II Aufl. } \\ & 1843 . \\ \text { Carus, } & \text { Grundzüge der vergl. Anatomie und } \\ & \text { Physiologie } 1825 .\end{array}$

Importante assinalar aqui que praticamente todos esses autores, e inclusive muitas dessas mesmas obras, cuja leitura Nietzsche planeja efetuar, são autores e obras que Lange tematizou na História do Materialismo. De certo modo, mais do que evidenciar a importância da obra de Lange para o pensamento nietzschiano, essa seleção de obras e autores representa também a preocupação de Nietzsche para com a temática científica. Ao nosso modo de ver, essa preocupação para com as questões relativas à ciência natural dá vida àquele embrião que, mais tarde, de um modo profundo e original, será capaz de desenvolver noções tão determinantes para o pensamento nietzschiano em profunda conexão com as ciências, sobretudo a física, biologia, psicologia e fisiologia, como é caso do pensamento do eterno retorno e da vontade de potência. Mais do que uma busca por obras que tratem da relação entre filosofia e ciência natural, o planejamento de Nietzsche inclui também obras quase que exclusivamente científicas.

Isso demonstra, uma vez mais que, mesmo entranhado na metafísica de Schopenhauer, mesmo diante de toda a dedicação à filologia, o jovem Nietzsche já se encontra profundamente marcado por aquele pensamento crítico que o levou a distanciar-se do cristianismo e que, gradualmente, o levará a adquirir sua independência também da metafísica e, com ela, de Wagner e Schopenhauer. Desse plano de leituras supracitado, Nietzsche não leu praticamente nenhuma dessas obras durante os anos em Leipzig, tampouco logrou dedicar-se apenas à filosofia. Entretanto, uma vez na Basileia, mesmo exercendo a profissão de filólogo, seu interesse pelas ciências naturais tornou-se ainda mais vivo, e aqui sim ele levará a cabo uma série de leituras cujas consequências marcarão até mesmo os anos da maturidade. É, portanto, a partir dessas leituras e impostações, em grande medida influenciadas pelos anos de Leipzig com especial destaque para a figura de Lange, que se desenvolvem as principais noções e argumentações que posteriormente virão à luz no Humano demasiado humano. Mas este é um outro assunto acerca do qual nos ocuparemos em um outro momento.

\section{Referências}

BROBJER, T H. Nietzsche's philosophical context: an intellectual biography. USA: University of Illinois Press: 2008.

CAMPIONI, G. et alii. Nietzsches persönliche Bibliothek. Supplementa Nietzscheana Volume 6. Berlim, Walter de Gruyter, 2003.

CRESCENZI, L. Verzeichnis der von Nietzsche aus der Universitätbibliothek in Basel entliehenen Bücher. (1868-1879), Nietzsche-Studien, 23 (1994), p. 388-442. 
FREZZATTI JR, W. A. "Haeckel e Nietzsche: aspectos da crítica ao mecanicismo no século XIX”, in: Scientiae Studia, Vol 1, no 4, 2003, p. 435-461.

GORI, P. Il meccanicismo metafisico: scienza, filosofia e storia in Nietzsche e Mach. Società Editrice il Mulino - Istituto Italiano per gli Studi Storici - Napoli: 2009.

"Nietzsche and mechanism". In: H. Heit, L. Heller (eds.), Handbuch Nietzsche und die Wissenschaften, De Gruyter. 2013, p. 119-137.

. La visione dinâmica del mondo: Nietzsche e la filosofia naturale di Boscovich, La cità del Sole, Napoli, 2007.

JANZ, C. P. Friedrich Nietzsche: uma biografia, volume I: infância, juventude, os anos da Basiléia. Tradução de Markus A. Hediger. Petrópolis, RJ: Vozes, 2016.

LANGE, F. A. Historia del materialismo. Vol. I e II. Traducción de Vicente Colorado. Daniel Jorro Editor, Madrid, 1903.

MITTASCH, A. Friedrich Nietzsches Naturbeflissenheit. Springer-Verlag: Heidelberg, 1950.

Friedrich Nietzsches als Naturphilosoph. Stuttgart, Alfred Kröner Verlag, 1952.

NIETZSCHE, F. W. Sämtliche Werke. Kritische Studienausgabe (KSA). G. Colli e M. Montinari (Hg.). Berlin: Walter de Gruyter, 1999. 15 Bn.

. Digitale Kritische Gesamtausgabe (eKGWB) - Digital version of the German critical edition of the complete works of Nietzsche edited by Giorgio Colli and Mazzino Montinari. The eKGWB is edited by Paolo D'Iorio and published by Nietzsche Source. Disponível em: http://www.nietzschesource.org/

SALAQUARDA, J. Nietzsche und Lange. Nietzsche Studien 7, 1978, p. 236-253. 133-16o.

. Der Standpunkt des Ideals bei Lange und Nietzsche, Studi Tedeschi, XXII, 1 (1979), p.

SCHLECHTA, Karl - ANDERS, Anni. Friedrich Nietzsche. Von den verborgenen Anfängen seines Philosophierens, Stuttgart-Bad Cannstadt 1962.

. Epistolario. Vol I, 1850-1869. Edizione italiana condotta sul texto critico stabilito da Giorgio Colli e Mazzino Montinari: Milano, 1976.

STACK, G. J. Lange and Nietzsche. Berlim - New York, 1983.

ZIMMERLI, W. C. Nietzsche's critique of truth and science, in B. Babich e R. Cohen. Nietzsche, Epistemology and Philosophy of Science; Nietzsche and the Science II, Dodrecht 1999, pp. 253-277.

Submissão: 01.10.2018 / Aceite: 27.11.2018. 